\title{
PRODUÇÃO DE CARNE BOVINA DO RIO GRANDE DO SUL E O MERCADO EXTERNO: EVOLUÇÃO E PERSPECTIVAS COM BASE NO TERRITÓRIO
}

\author{
Luiza Araujo Damboriarena ${ }^{1}$ \\ João Garibaldi Almeida Viana ${ }^{2}$
}

\begin{abstract}
Resumo
O presente trabalho tem como objetivo analisar o mercado externo da carne bovina do Rio Grande do Sul e suas potencialidades em prol do desenvolvimento com base no território das regiões Fronteira Oeste e Campanha do Estado. O estudo foi realizado através de uma pesquisa do tipo exploratória e descritiva, na qual foi aplicado um questionário semiestruturado em uma amostra de 67 produtores/entidades de apoio/indústria, a fim de ampliar o conhecimento sobre as exportações de carne bovina e compreender a visão dos agentes sobre seu impacto no território. Inferiu-se que o Rio Grande do Sul produz uma carne diferenciada em termos de qualidade, porém, mesmo apresentando um potencial competitivo territorial, não vem recebendo um diferencial econômico na comercialização com o mercado externo. Além disso, os agentes da cadeia indicam que as características do território são fatores importantes para o fortalecimento do setor. Ressalta-se que aspectos como tradição, vocação, bioma pampa, entre outros, podem ser melhor comunicados a fim de diferenciar o produto. Concluiu-se que
\end{abstract}

\footnotetext{
${ }^{1}$ Bacharel em Administração pela Universidade Federal de Santa Maria, especialista em Desenvolvimento de Regiões de Fronteira pela Universidade Federal do Pampa. Atualmente cursa mestrado em Administração na área de estudos organizacionais na Universidade Federal do Rio Grande do Sul. E-mail: luizadamboriarena@hotmail.com 2 Professor Adjunto da Universidade Federal do Pampa, Campus Santana do Livramento. É doutor em Agronegócios pela Universidade Federal do Rio Grande do Sul, mestre em Extensão Rural e graduado em Zootecnia pela Universidade Federal de Santa Maria.E-mail: joaoviana@unipampa.edu.br
} 
aliar características territoriais ao mercado externo podem trazer benefícios em prol do desenvolvimento das regiões produtoras.

Palavras-chaves: Bovinocultura de corte, exportações, desenvolvimento territorial.

\title{
BEEF PRODUCTION IN RIO GRANDE DO SUL AND FOREIGN MARKET: EVOLUTION AND PERSPECTIVE BASED ON TERRITORY
}

\begin{abstract}
This work aims to analyze the foreign market of beef cattle from Rio Grande do Sul and its potential for development based on the territory of the regions Fronteira Oeste e Campanha of the State. The study was conducted through an exploratory and descriptive research, in which was applied semi-structured questionnaire in a sample of 67 producers / support organizations / industry in order to expand knowledge on exports of beef and understand the vision agents over their impact on the territory. Inferred that Rio Grande do Sul produces a meat differentiated in terms of quality, but even presenting a competitive territorial potential does not come getting a differential in economic trade with foreign markets. Moreover, the chain agents indicate that the characteristics of the territory are important factors in strengthening the sector. It is highlighted that aspects such as tradition, vocation, Pampa biome, among others, can be better communicated to differentiate the product. Concluded that combine characteristics territorial with foreign markets can provide benefits for development of regions.
\end{abstract}

Key words: Beef cattle, exports, territorial development. 


\section{INTRODUÇÃO}

O crescimento da renda per capita e das taxas de urbanização nos países em desenvolvimento, somado ao crescimento da população mundial estimada pelo UNFPA (2013) em aproximadamente 9 bilhões pessoas até 2050, são aspectos capazes de alavancar as demandas mundiais por alimentos. Ainda, estudo da FAO (2013) prevê uma elevação significativa na demanda por produtos agrícolas até 2019, com abreviado aumento da produção, fato que pode gerar uma sustentação dos preços dos alimentos em patamares elevados nesse período.

Nesse cenário, o Brasil vem apresentando importante crescimento no comércio internacional do agronegócio, firmando-se como um dos principais produtores e exportadores de alimentos para mais de 200 países, na qual a bovinocultura de corte possui grande destaque, tanto em termos de abastecimento do mercado interno, quanto nas negociações internacionais. O país é líder nas exportações desse segmento desde 2004, representando uma parcela de $20 \%$ no mercado internacional, vendendo seus produtos para mais de 180 nações (MAPA, 2012b). Em relação à oferta, o Brasil apresenta-se como um dos principais exportadores de alimentos, fibras e seus processados, sendo, também, um dos poucos países ainda com capacidade de expansão de sua área de agricultura e/ou pecuária (FREITAS, 2012).

A partir do crescimento das exportações da carne bovina brasileira, a concorrência dos mercados gerou uma reestruturação das práticas de gestão, tecnológicas, sanitárias e legais nesta cadeia produtiva. Por outro lado, a profissionalização da atividade, bem como sua modernização e adequação ao processo produtivo e transformação às diversas normas de qualidade e sanidade, embora sirvam para aperfeiçoar o negócio da carne, apresentam um custo bastante alto, requerendo elevados investimentos de longo prazo. Estes desafios necessitam de uma demanda de recursos que não consegue ser efetivada devido a real posição econômica de grande parte dos partícipes de cada elo da cadeia, sobretudo de pequenos produtores e frigoríficos (LIMA e MACEDO, 2011).

Não obstante ao bom desempenho da atividade pecuária brasileira, Malafaia et al. (2006) relatam que o processo de globalização teve forte impacto na bovinocultura de corte do estado do Rio Grande do Sul, principalmente em virtude da concorrência com os países do MERCOSUL. Nesse cenário, diversos produtores foram excluídos do processo produtivo e muitas indústrias faliram. 
Para os mesmos autores, os produtores do estado vêm enfrentando dificuldades diante da concorrência de novos polos de atividade pecuária, como, por exemplo, os estados da região Centro Oeste, especificamente em relação às exportações de carne bovina, que, devido exigências do mercado internacional, demandam maior qualificação no processo produtivo do que a produção para 0 mercado doméstico.

Assim, sob esse contexto, identifica-se com clareza uma possível perda de espaço no mercado externo, bem como a redução da competitividade do Rio Grande do Sul em relação aos estados concorrentes.

Em contrapartida, para Malafaia et al (2006), o Rio Grande do Sul possui um destacado potencial competitivo, advindo de recursos estratégicos presentes em seu território, que possibilitam produzir uma carne diferenciada, com maior qualidade e melhor apreciada no exigente mercado externo. Porém, ainda necessitam serem trabalhadas ações de forma coordenada a fim de obter vantagens competitivas sustentáveis.

Os problemas apontados pelos quais se defronta a cadeia da carne bovina do Rio Grande do Sul, bem como a possibilidade de reverter este cenário mediante a eficiente exploração dos recursos estratégicos presentes em seu território, são elementos que se tornaram instigadores de investigação.

Diante do exposto, o trabalho teve como objetivo analisar o mercado externo de carne bovina do Rio Grande do Sul e suas potencialidades em prol do desenvolvimento territorial das regiões Fronteira Oeste e Campanha do estado, áreas tradicionais na bovinocultura de corte e detentoras dos maiores rebanhos bovinos do estado.

\section{REFERENCIAL TEÓRICO}

O referencial busca discutir conceitos de mercado externo e exportação, a partir da visão do desenvolvimento regional e fundamento pela teoria da base exportadora, passando pela sua evolução ao apresentar os conceitos de desenvolvimento territorial. Esta construção visa dar base para uma reflexão de como aspectos de exportação e mercado externo, combinados com a valorização e diferenciação do território, podem alavancar o desenvolvimento de uma região.

Objetiva-se, com esta discussão, fundamentar a análise da capacidade dos fatores internos da região - como o potencial 
produtor de carne bovina do Rio Grande de Sul - de transformar um impulso externo de crescimento econômico, como a elevação da demanda por alimentos, na geração de desenvolvimento regional, com base na perspectiva territorial e na teoria da base exportadora.

\section{O MERCADO EXTERNO E A TEORIA DA BASE EXPORTADORA}

O mercado externo proporciona, em princípio, melhores condições de desenvolvimento para os países de recursos naturais apropriados à agricultura. Através da exportação obtém-se uma ampliação de mercado que condiciona melhores preços e uma alocação intensiva de recursos na produção de bens para os quais o país tem maior vantagem comparativa; o que não motiva apenas maior produtividade dos recursos dirigidos, como também possibilidade de importar produtos (matérias-primas e manufaturados) e conhecimentos técnicos que não teriam competência de ser produzidos, de imediato ou ao mesmo custo, no próprio país (PAIVA, 1979).

A base econômica de uma determinada região é pautada pelo conjunto de variáveis exógenas influenciadas por forças externas à região, como a renda dos consumidores mundiais, na aquisição de produtos regionais, a política pública em nível federal na região, as deliberações dos investidores de demais regiões ou países em relação à região, etc. Estas decisões podem ser independentes do nível da atividade local, assim como medidas regionais econômicas. As atividades não básicas, também compreendidas como as atividades de mercado interno, são determinadas como a parcela da produção regional consumida pela população local da região. Elas formam a diferença entre as atividades totais e as atividades da base econômica, dependentes do coeficiente de renda da região (SOUZA, 2009).

Segundo Souza (2009), através de estudos sobre a base econômica foi possível concluir que "existe um conjunto de atividades econômicas motoras do crescimento urbano e regional". A premissa é de que tais atividades são as que obtêm mercados exteriores à região, envolvendo a economia nacional e mundial. Após, foi constatado que fatores exógenos, a exemplo dos investimentos locais, também têm impacto no crescimento econômico. Dessa forma, a base econômica de uma região passou a conglomerar as exportações regionais, os gastos governamentais na respectiva área, os afluxos de capitais líquidos e demais rendas que 
possam provocar resultados multiplicadores sobre as atividades internas de mercado.

Assim, as exportações regionais representam a parte mais expressiva da base econômica e desempenham maiores impulsos na economia local (SOUZA, 2009). Ainda, Souza (2009, p. 86) comenta que a intenção principal é de que:

[...] as exportações exercem um efeito multiplicador sobre o setor de mercado interno mais do que proporcionalmente à variação original quando se considera o conjunto da economia. Portanto, segundo a teoria da base de exportação, a fonte de dinamismo de crescimento regional é a demanda externa, o poder de compra e o tamanho da população das demais regiões e países consumidores. Os exportadores compram insumos de atividades de mercado interno, pagam salários e outras rendas que são gastas no mercado local. O aumento do emprego do setor exportador expande 0 emprego e a renda das atividades de mercado interno.

Um dos embasamentos da teoria da base de exportação são as economias de escala obtidas através da produção para um mercado mais vasto do que aquele demarcado pelas fronteiras regionais. Uma pequena região não teria condições de produzir todo consumo que sua população necessita. De tal forma, é gerada a necessidade de obter recursos para importar bens e serviços de outras regiões do mercado interno e externo. Com a produção em ampla escala, reduzem-se os custos médios ao nível da competição mundial, o que gera um conjunto de atividades básicas, e estas, consequentemente, têm efeitos de encadeamentos sobre o mercado interno. Ainda, devido ao fato de muitas regiões possuírem mercado local mais restrito, a ampliação das exportações é justificada em virtude das indústrias necessitarem escala mínima para sua eficiência (SOUZA 2009).

Para Souza (2002), as vantagens de uma economia alicerçada no crescimento das exportações são:

a) Complementar o mercado interno: mesmo que o setor de mercado interno (SMI) trabalhe com capacidade ociosa, isto é, com a 80 
demanda interna saturada, o consumo interno cresce abaixo que a oferta interna, logo, as exportações têm a função de reduzir os estoques não vendidos.

b) Gerar economias de escala: o aumento das exportações faz com que os custos fixos sejam diluídos, reduzindo os custos médios. Assim, ocorre um aumento da margem de lucro, que estimulará os investimentos, gerando novos empregos no SMI pelos resultados de multiplicação.

c) Melhorar a eficiência produtiva interna: a especialização e a manutenção de elevados padrões de eficiência e competitividade são consequências diretas da concorrência nos mercados externos. Os contatos com esses mercados trazem novos conhecimentos que são repassados ao mercado doméstico.

d) Melhor aproveitamento dos recursos disponíveis: com o aumento das exportações ocorre uma redução da ociosidade da economia, aumentando o emprego dos recursos disponíveis como terras, minerais, mão-de-obra, empresariado e capitais.

e) Interdependências tecnológicas e econômicas: o crescimento das exportações gera reflexos no mercado doméstico através dos efeitos de multiplicação da renda e do emprego, em decorrência da demanda de serviços e pela compra de insumos e bens de capitais produzidos pelo mercado interno.

No entanto, sob um viés antiexportação, o pressuposto de que as exportações exerçam papel de motor no desenvolvimento de regiões e países não foi muito bem acolhida pelos economistas do desenvolvimento, especialmente na América Latina. Os pretextos, entre outros, foram baseados nas ideias Cepalinas, da Teoria da Dependência, pelas relações assimétricas entre as economias centrais e periféricas, que gera a dependência econômica; a ocorrência de riscos elevados para o capital internacional; e, principalmente, a incapacidade para propagação interna, setorial e espacialmente, consequência dos encadeamentos derivados dos investimentos no setor exportador (SOUZA 2009).

Diversificar a base exportadora e desenvolver mecanismos para difusão dos efeitos em série no âmbito do mercado doméstico torna-se a preocupação vital, conscientemente ou não, das regiões que, tradicionalmente, vêm obtendo crescimento a partir das exportações de produtos básicos (SOUZA 2009).

A teoria da base exportadora foi formulada sob a abordagem do desenvolvimento regional, no entanto suas idéias fundamentais também são aplicáveis em termos de comércio internacional. A partir do exposto, é possível concluir que a teoria da 
base exportadora considera as exportações como o motor do crescimento local ou regional, a partir de um impulso externo (exógeno) à região, ou seja, a demanda de seus produtos por outras regiões ou países, tendo seu alcance determinado através do efeito multiplicador que as exportações produziriam sobre as atividades locais.

Logo as exportações constituem-se numa condição necessária para o desenvolvimento regional, porém não suficientes. Assim, ressalta-se a necessidade de um olhar para o território, ou seja, para as condições e características não apenas exógenas ao ambiente, mas pertencentes às condições locais, tornando-se auxiliares no processo de desenvolvimento.

\section{A PERSPECTIVA DO DESENVOLVIMENTO TERRITORIAL}

Ao analisar o panorama presente de uma região ou território, não se pode deixar de admitir, segundo Schneider (2004), que o cenário atual é fortemente marcado por uma ampliação da interdependência nas relações sociais e econômicas em escala mundial.

\begin{abstract}
A emergência da abordagem territorial do desenvolvimento pressupõe que o nível adequado de tratamento analítico e conceitual dos problemas concretos deva ser o espaço de ação em que transcorrem as relações sociais, econômicas, políticas e institucionais. Esse espaço é construído a partir da ação entre os indivíduos e o ambiente ou contexto objetivo em que estão inseridos. Portanto, o conteúdo desse espaço é entendido como o território. Mas não se trata apenas do entendimento teórico e abstrato, pois esta perspectiva também propõe que as soluções e respostas normativas aos problemas existentes nesses espaços encontram-se nele mesmo (SCHNEIDER, p. 12, 2004).
\end{abstract}

O território apresenta uma alusão globalizada, algo que vem sendo construído em consonância ao conceito de globalização, contrapondo-se, por vezes, a este devido às possibilidades que proporciona de distinguir e valorizar as peculiaridades locais e 82 
regionais, no confronto à aspiração uniforme da ideia de globalização. Outras vezes, a questão do território apresenta oportunidades de inclusão do particular no global, pelas propriedades de desenvolvimento de potencialidades locais e regionais, gerando valor e visibilidade (GEHLEN e RIELLA, 2004).

Para Muls (2008), avaliar o território como um ator, como um sujeito definido através da ação grupal e da construção de instituições locais, significa por em confronto os princípios de funcionamento de uma economia globalizada às estratégias supranacionais derivadas da resposta e da reação aos imperativos da concorrência internacional. Constitui opor o local ao global e compreender que as estratégias locais retroagem em relação às forças globais, levando-as a redirecionar suas leis de funcionamento, e então, dar início a um movimento independente de crescimento e de auto-regulação. Tais reações que se exprimem nos espaços supranacionais trazem exemplos de comportamento que interrogam as teorias tradicionais do desenvolvimento. Uma capacidade de se adaptar e de inovar, novas estratégias de desenvolvimento, novas formas de valorizar e de partilhar a produção decorrem dos espaços supranacionais e se apresentam como um fator explicativo que não fazia parte das teorias tradicionais do desenvolvimento.

$\mathrm{O}$ conceito de desenvolvimento territorial sugere algo mais do que somente outra forma de tornar compreensíveis as realidades do desenvolvimento regional e local, em diferentes níveis. Trata-se de uma mudança de paradigma nas teorias acerca do desenvolvimento regional. Com a questão de desenvolvimento territorial, as ciências sociais, ao adotar uma abordagem multidisciplinar e interdisciplinar, conquistam novos instrumentos, que são capazes de distinguir a importância do território como uma construção social, e não só como realidade biofísica tangível (JEAN, 2009).

Além disso, o autor aponta que a noção de desenvolvimento territorial rompe com a tradição de estudos antigos sobre 0 desenvolvimento regional, porém não disponibiliza até o momento um arcabouço de doutrinas ou teorias já consolidadas.

Schneider (2004) complementa que a abordagem regional enfraquece sua capacidade explicativa enquanto referência teórica e conceitual e passa a ser insuficiente como instrumento para planejar normas das ações práticas do Estado e dos agentes políticos. É nesta conjuntura que ganha relevância o território, a partir de então como uma noção com regulamento operacional, permitindo superar os condicionantes e limitantes do aporte regional. Nesta definição, o 
território surge como um processo ligado à globalização, especialmente pela nova dinâmica econômica e produtiva, no qual as decisões e iniciativas são tomadas e atreladas em função do território.

A dinâmica territorial do desenvolvimento compreende o conjunto de ações incluídas no processo de desenvolvimento, cometidas por atores/agentes, organizações/instituições de uma sociedade percebida histórica e territorialmente. O seu modo é sustentado pela presunção de que o desenvolvimento possui relação direta com a dinâmica (social, econômica, ambiental, cultural e política) dos distintos territórios. Conforme o tipo de ação, passiva ou ativa, dos atores territoriais no amparo dos seus interesses, diante do processo de globalização, os territórios adotam alternativas de desenvolvimento que os beneficiam ou que os prejudicam, em desiguais intensidades, transformando-se em territórios do tipo "inovadores/ganhadores" ou "submisso/perdedores". Desse processo dialético global-local, de ação-reação, pelas quais os anseios são delineados na esfera global, decorrem as diferenciações ou desigualdades territoriais (DALLABRIDA 2007).

Segundo Jean (2009), o território concebe um desafio na definição de que a noção regional traduz uma procura coletiva de relacionamento, além da busca da satisfação dos interesses estritamente individuais, sempre envolvida a um dado território cuja identidade e cujos limites são mais ou menos bem constituídos; este desafio passa a ser também um desafio político, quando diferentes territórios de uma mesma entidade sociopolítica almejem um desenvolvimento levando em consideração suas potencialidades, sem acentuar as desigualdades regionais. O território é o fruto do desenvolvimento, pois este só tem significado se proporcionar um ambiente sustentável, indo além do atendimento das necessidades pessoais, implicando na promoção de um desenvolvimento territorial exitoso, 0 qual satisfaz à própria demanda social de desenvolvimento.

No momento que a noção de desenvolvimento territorial foi ganhando força, as discussões em relação ao papel da agricultura e do espaço rural também foram se transformando. Na realidade, a questão territorial gerou a superação do aspecto setorial das atividades econômicas (agricultura, indústria, comércio, serviços, etc.), assim como a dicotomia do espaço rural/urbano ou campo/cidade. $\mathrm{Na}$ abordagem do território, as dicotomias e os antagonismos são trocados pelo escrutínio da variedade de ações, estratégias, fluxos e rumos que os atores (pessoas, empresas ou 
instituições) adotam com vistas a sua reprodução social e econômica. A viabilização dos atores e dos territórios estará sujeita do modo particular e específico de cada forma de intercâmbio, das decisões e racionalidades, não havendo obrigações de qualquer ordem ou evolução predeterminada. Como reflexo, a diversidade e a heterogeneidade social e econômica dos territórios emergem, e constituem a linha característica dos diferentes caminhos e trajetórias que podem ser traçados rumo ao desenvolvimento (Pecqueur, 1992; 1996 apud Schneider, 2004).

Neste contexto, conforme Schejtman e Berdegué (2003), para se tratar o desenvolvimento rural na perspectiva territorial é necessário levar em consideração sete elementos.

a) É num ambiente cada vez mais competitivo, marcado pela ampla difusão do progresso técnico e do conhecimento, que dão as chances de sobrevivência das unidades de produção.

b) A inovação tecnológica é um fator chave para elevar a produtividade da mão-de-obra e aumentar a renda da população rural.

c) A competitividade é um fenômeno sistêmico e depende do ambiente onde se está inserido.

d) A demanda externa exerce um papel decisivo sobre as transformações produtivas locais e territoriais, sendo, portanto, fundamental para o aumento da produtividade e da renda.

e) Vínculos rural-urbanos são fundamentais ao desenvolvimento de atividades agrícolas e não-agrícolas em um território.

f) O desenvolvimento institucional tem importância fundamental para o desenvolvimento dos territórios.

g) O território não é um espaço físico que existe objetivamente, mas uma construção social, ou seja, um conjunto de relações sociais que se originam e se expressam em uma identidade e em um sentimento de pertencimento compartilhado por agentes públicos e privados.

A partir desta construção social, para Abramovay (2000), em uma visão territorial do desenvolvimento é possível descobrir potenciais que, até o presente momento, o meio rural não havia revelado à sociedade. Percebido como a base de produção agrícola, seu destino dificilmente resiste ao drama do esvaziamento social, cultural, econômico e político. Quando, todavia, o meio rural passa a ser entendido como a base de um conjunto variado de atividades, funções e mercados em potencial, e não como uma simples 
sustentação geográfica de um segmento (a agricultura), seus horizontes passam a ser ampliados.

Da mesma forma, Schneider (2004), no intento de caracterizar os modos e as particularidades com que acontece 0 processo de intermediação dos territórios rurais com o ambiente externo, reconhece seis contornos distintos pelos quais acontece a articulação e a intervenção dialética, afirmando que não se trata de uma via unilateral:

a) A forma clássica, por meio da produção agrícola e do abastecimento de matérias-primas, ainda apresenta importância essencial para a sociedade, principalmente quando é levada em consideração a função das cadeias agroindustriais e do sistema agroalimentar para muitas localidades e áreas rurais.

b) A relevância de ser repensada a dinâmica das relações rural-urbanas ou campo-cidade.

c) A importância da pluriatividade das famílias que habitam no meio rural e trabalham em atividades não-agrícolas longe da propriedade e, não raro, do próprio ambiente rural. consumidores.

d) As novas formas de relacionamento entre produtores e

e) A revalorização urbana do rural, através do interesse por atividades diferenciadas, não-rotineiras; ações de preservação e valorização do meio ambiente; patrimônio histórico, paisagístico, cultural; incremento populacional pelo retorno de populações de aposentados e antigos moradores; descentralização de atividades empresariais.

f) Nas articulações externas dos territórios rurais assentadas sobre a dimensão sociocultural, pois é inegável o impacto determinante dos meios de comunicação e dos padrões de consumo da sociedade.

Neste sentido, Dullius et al. (2008) concluíram que as articulações entre território, identidade, cultura e mercado consentem a interpretação do ambiente geográfico, calcado por uma identidade construída socialmente, compondo vínculos de proximidade e interdependência, colaborando com a qualidade e benefícios dos produtos e serviços locais, tornando-se mais competitivo e, portanto, obtendo maior acesso aos mercados.

Portanto, através dos conceitos revistos até o momento, o presente trabalho objetiva realizar uma conexão entre mercado externo e base exportadora, esta última como multiplicadora da renda de uma determinada região em articulação com os atores e recursos locais pela perspectiva territorial, somando aspectos 
exógenos e endógenos na busca pelo desenvolvimento. Dentro desse contexto, é analisado o setor da bovinocultura de corte do Rio Grande do Sul e a atual situação da cadeia de carne bovina gaúcha em relação às exportações nacionais.

Diante do aporte teórico exposto, contemplando a importância da noção de territorialidade, é possível pensar no segmento da bovinocultura de corte como um propulsor do desenvolvimento regional, ampliando os recursos estratégicos e o diferencial competitivo que o Rio Grande do Sul possui no setor. No entanto, cabe um esforço analítico no que tange ao papel do estado no mercado brasileiro e quais aspectos territoriais podem alavancar as exportações e agregar potencial competitivo ao setor gaúcho.

\section{METODOLOGIA}

A pesquisa caracterizou-se como exploratória e descritiva, por meio de técnicas de pesquisa bibliográfica, de campo e análise de dados primários e secundários a fim de ampliar o conhecimento sobre o mercado externo da cadeia de carne bovina do Rio Grande do Sul. Os procedimentos metodológicos possibilitaram uma análise setorial do mercado e das exportações nacionais e gaúchas do produto, bem como pontuar aspectos territoriais importantes para valorização da carne bovina regional.

A primeira fase constituiu-se na coleta de dados secundários referentes à dinâmica das exportações de carne bovina no Rio Grande do Sul e Brasil. Os dados coletados referiram-se as quantidades (toneladas) e valor bruto (dólares) da carne bovina exportada do Rio Grande do Sul e do Brasil no período compreendido entre 1997 e 2011. As séries temporais foram coletadas junto ao Ministério da Agricultura, Pecuária e Abastecimento por meio das Estatísticas de Comércio Exterior do Agronegócio Brasileiro (Agrostat).

As variáveis de quantidade e valor exportado foram analisadas por meio de estatística descritiva, com o uso de frequências e representação gráfica.

A segunda fase do trabalho consistiu de pesquisa de campo com a aplicação de questionário semiestruturado com agentes da cadeia produtiva bovina do Rio Grande do Sul. Esta etapa buscou demonstrar as características, motivações e percepções apresentadas sobre os fatores relevantes que afetam a diferenciação da carne bovina do Rio Grande do Sul com vistas ao mercado externo. Ainda, os questionários buscaram captar as características 
do território que podem ser exploradas para impulsionar a cadeia produtiva da carne bovina da região estudada.

A coleta de dados foi realizada a partir de uma amostra do tipo não probabilística por conveniência, através de questionários enviados por meio eletrônico. A pesquisa foi direcionada para produtores rurais, representantes da indústria frigorífica e profissionais de instituições atuantes na cadeia da bovinocultura, a fim de obter uma ampla e diversa percepção do fenômeno.

Foram obtidos 67 questionários oriundos de distintas cidades do Rio Grande do Sul, porém com predominância de municípios da Fronteira Oeste e Campanha do estado devido à concentração da produção nestas regiões.

Após a coleta, os dados foram organizados e tabulados. As variáveis quantitativas foram trabalhadas a partir de estatística descritiva por meio de medidas de localização e distribuição de frequências e os dados qualitativos foram analisados no seu conteúdo, considerando os elementos previamente definidos para a investigação. Para discussão dos resultados utilizou-se como apoio os conceitos e pressupostos apresentados na fundamentação teórica da pesquisa.

\section{RESULTADOS E DISCUSSÃO}

Nesta etapa é apresentada a análise de dados secundários do mercado externo e os resultados da pesquisa acerca da percepção dos agentes da cadeia de carne bovina do Rio Grande do Sul sobre aspectos de exportação, território e seu impacto no desenvolvimento da região.

\subsection{Análise das Exportações de Carne Bovina do Estado do Rio Grande do Sul e do Brasil}

A Figura 1 apresenta um comparativo do comportamento do volume de exportação de carne bovina do Brasil e do Rio Grande do Sul de 1997 a 2011. Nota-se que tanto as exportações brasileiras como do estado apresentaram forte crescimento até o ano de 2006. No entanto, após esse ano, o volume exportado vem caindo, com queda mais acentuada no Rio Grande do Sul.

Possíveis causas desse comportamento de queda são a desvalorização do dólar frente ao real no período e o aumento do poder aquisitivo da população brasileira, aquecendo o mercado 
interno e possibilitando oferta de carne bovina para o mercado doméstico.

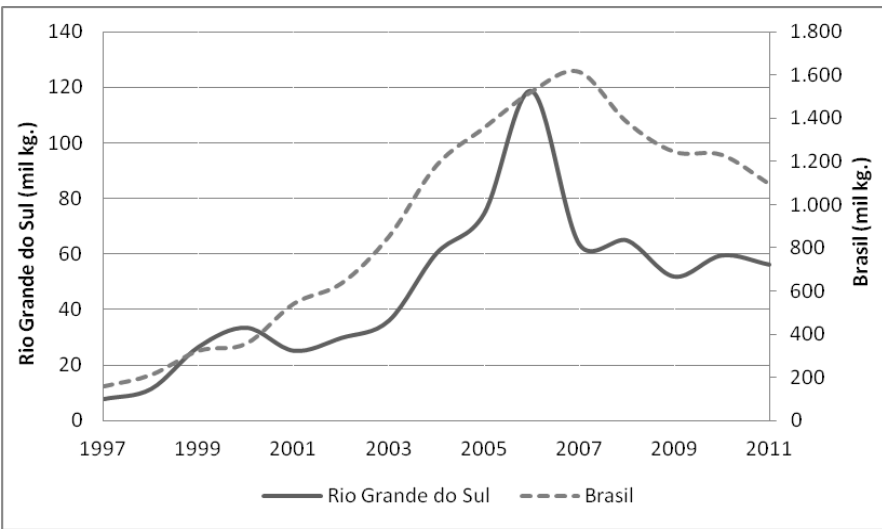

Figura 1 - Quantidade de carne bovina exportada - Brasil e Rio Grande do Sul.

Fonte: MAPA (2012a)

Segundo o IBGE (2009), em 2007 começou a ocorrer redução na oferta de animais para abate, apresentando crescimento somente a partir 2009, em decorrência da recuperação nas transações com o mercado externo e da demanda interna. Outra justificativa para queda nas exportações e diminuição do abate estaria na desaceleração da economia frente à crise mundial em 2008.

A Figura 2 representa um comparativo dos preços médios pagos pela carne brasileira e pela carne gaúcha exportada. Observase que as curvas apresentam o mesmo comportamento, no qual as tendências de quedas e elevações possuem similaridade.

Segundo dados das exportações brasileiras de carne bovina (MAPA, 2012a), o país exportou em 2011 a um valor médio de US\$ 4,88 por quilograma de carne bovina, e para o mesmo ano-base o Rio Grande do Sul exportou com valor de US\$ 4,42 por quilograma. Dessa forma é possível verificar que o valor médio recebido pela carne gaúcha em 2011 foi aproximadamente 10\% inferior ao valor médio pago pela carne brasileira. 


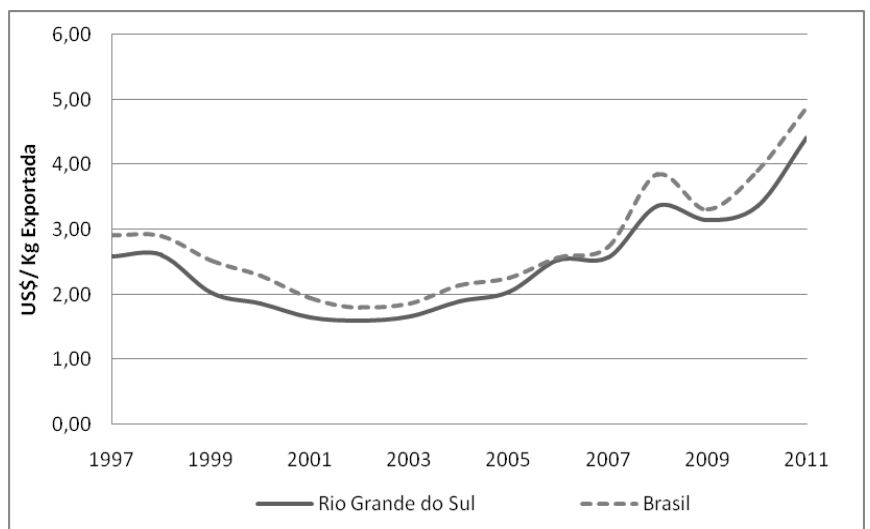

Figura 2 - Valor das exportações do Brasil e Rio Grande do Sul - Dólares por quilograma exportado.

Fonte: MAPA (2012a)

Ao analisar o comportamento do valor das exportações de carne bovina no período 1997 a 2011, observa-se um crescimento, especialmente, após o ano de 2002. No entanto, o valor do produto gaúcho mantém-se, ao longo de toda a série, abaixo do valor médio de exportação da carne bovina brasileira.

Assim, constata-se que apesar da carne bovina gaúcha apresentar um diferencial de qualidade na percepção dos agentes da cadeia produtiva, no mercado externo esse produto não apresenta diferencial de preço, visto que a média do preço por quilograma da carne bovina exportada pelo Brasil se mostra superior à do Rio Grande do Sul, indicando que o produto de outros estados brasileiros recebe remuneração maior, elevando a média nacional.

Outro ponto importante a ser observado é a comparação da evolução da participação do rebanho gaúcho no rebanho nacional e a participação do estado no total das exportações brasileiras, representadas pela Figura 3 . 


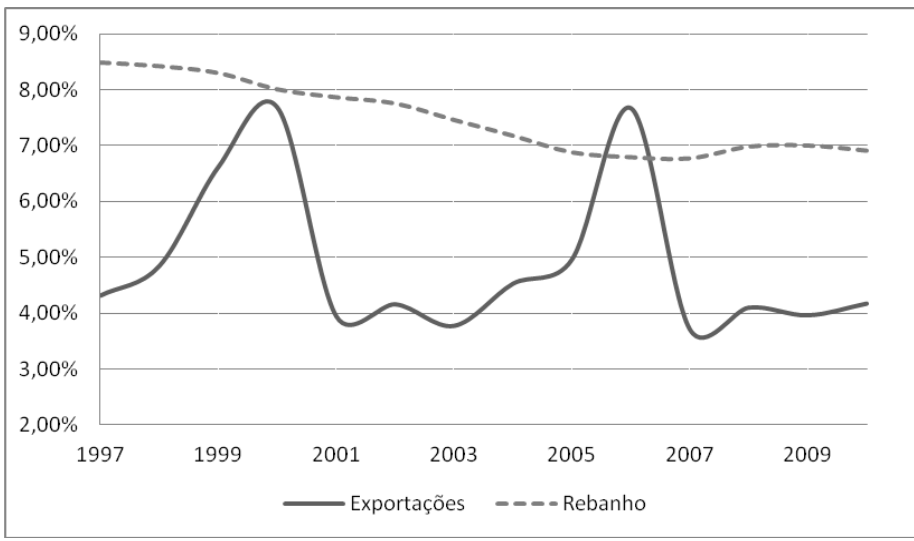

Figura 3 - Evolução da participação do Rio Grande do Sul nas exportações totais brasileiras e no rebanho nacional.

Fonte: MAPA (2012a; 2012b).

A participação das exportações gaúchas é inferior à sua participação no efetivo total do rebanho brasileiro, ou seja, a trajetória da participação gaúcha no rebanho nacional não possui relação direta com o comportamento da participação do Rio Grande do Sul nas exportações nacionais. Isto fica evidenciado pelo comportamento distinto das curvas de participação, no qual os movimentos de quedas e elevações não se acompanham.

Ainda, ressalta-se que em quase todo o período analisado, o Rio Grande do Sul apresentou menor participação nas exportações brasileiras do que no rebanho nacional. Isso indica que o estado se posiciona com uma pequena parcela do comércio internacional de carne bovina do Brasil, chegando, nos últimos anos, com uma representação de $4 \%$ a $5 \%$ do total exportado. Mesmo com a sua participação no rebanho nacional em queda, o Rio Grande do Sul, apenas no ano de 2006, alcançou parcela de exportação superior à sua representação do rebanho brasileiro.

Um fator que pode ser considerado para explicar esses movimentos é o preço do boi gordo em termos regionais, uma vez que um preço maior pode justificar um aumento de produção por parte do pecuarista e/ou mudança no sistema de produção, gerando variação na participação dos estados, bem como estímulo ou desestímulo ao acesso ao mercado externo. 
Segundo a ABIEC (2012), as maiores plantas frigoríficas estão concentradas nos estados do Mato Grosso (18), São Paulo (14), Goiás (10), Mato Grosso do Sul (9), Rondônia (9), Rio Grande do Sul (6), fator que pode ter influência nos números de exportações dos estados.

Além disso, segundo Fürstenau (2004), houve um deslocamento da produção pecuária para os estados da região Centro Oeste e perda de posição de regiões tradicionais de pecuária de corte, como Sul e Sudeste. Esse movimento ocorreu em função da expansão da fronteira agrícola para região Centro Oeste a partir de década de 1970. A autora ainda comenta que os estados dessa região obtêm maiores vantagens em termos de "ganhos de escala" e diferenças climáticas, que geram uma maior lucratividade. Fürstenau (2004) também explica que no ano de 2002, e especialmente em 2003, o aumento da produção de soja no Rio Grande do Sul foi responsável por estabelecer um novo e forte ciclo de avanço da agricultura sobre terras de atividade pecuária.

Assim, mesmo que o mercado interno absorva grande parte da produção de carnes no país, $80 \%$ segundo a ABIEC (2012), incentivar a exportação gera uma valorização dos preços no mercado, com consequências positivas através do efeito multiplicador que ela exerce nas atividades locais, como aumento da eficiência produtiva, maior aproveitamento dos recursos disponíveis, diminuição dos custos de escala e da capacidade ociosa, e principalmente pelos reflexos na economia como a geração de empregos e aumento da renda

Somado a isso, com as projeções futuras da demanda mundial por alimentos, estima-se aumentos significativos e a conquista do Brasil de maiores espaços no mercado internacional, ou seja, um mercado potencial a ser explorado.

\subsection{Análise das Potencialidades do Mercado Externo e o Desenvolvimento do Território}

$\mathrm{Na}$ coleta dos dados primários, foi questionada a percepção acerca da existência de um diferencial na carne bovina gaúcha. A partir da análise dos resultados foi possível concluir que ambos os grupos de produtores rurais e entidades de apoio/indústria frigorífica concordam em mais de $90 \%$ que a carne gaúcha se diferencia da produção nacional.

Acerca da valorização e remuneração do mercado em relação a esse diferencial percebido na carne do Rio Grande do Sul, 
ambos os grupos mantêm semelhança nas respostas, onde $62 \%$ dos produtores rurais e $71 \%$ dos representantes das entidades de apoio/indústria entendem que o mercado externo não está valorizando o diferencial da carne gaúcha.

Estes resultados corroboram com os dados revelados pelo MAPA (2012a), no qual é apontado que a carne bovina do Rio Grande do Sul é remunerada abaixo da média nacional. Sendo assim, é possível concluir que esse diferencial, percebido por todos agentes da cadeia, não representa força econômica na comercialização externa desse produto. Embora o Rio Grande do Sul possua vocação na produção de carne, com diferencial competitivo e recursos estratégicos no seu território, esses atributos não se convertem em números de produtividade e remuneração.

O modelo de produção do Rio Grande do Sul se diferencia de outras regiões do Brasil em termos de raças, pastagens, estrutura fundiária, etc. Alguns destes fatores dificultam a competição por custos com demais regiões brasileiras. A produção do Rio Grande do Sul tem forte afinidade com os modelos do Uruguai e da Argentina, e estes últimos são reconhecidos por produzir uma carne de qualidade diferenciada a alto custo e preço de produto diferenciado.

Dessa forma, a matéria-prima produzida em solo gaúcho é distinta daquela produzida nas demais regiões brasileiras, mas não vem obtendo retorno econômico superior perante as suas concorrentes, ou seja, o Rio Grande do Sul não recebe esse diferencial quando vende a sua produção ao mercado externo, conforme os dados do MAPA (2012a) e dos participantes da pesquisa, produtores rurais e entidades de apoio/indústria.

Assim, pode-se inferir que o estado está comercializando sua carne de "qualidade" para regiões e países dispostos a pagar por quantidade, sendo remunerado muito mais pelo seu peso do que por suas especificidades e valor agregado, característica típica de um produto commodity.

É nesta característica de mercado que se insere o conceito de território e as reflexões em torno das características locais. Esse cenário de baixa valorização pode ser modificado com a consciência da importância de se explorar características do território como forma de valorizar o produto. Conforme Figura 4, tanto produtores como entidades de apoio/indústria afirmam que a exploração de características do território, como especificidades produtivas, tradição, costumes, aspectos geográficos, podem diferenciar o produto e gerar desenvolvimento para as regiões produtoras. 


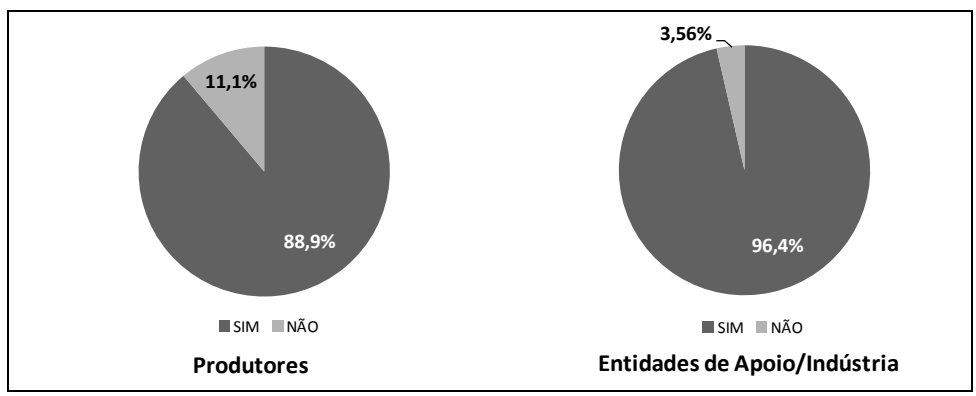

Figura 4 - Exploração de características do território no desenvolvimento das regiões produtoras.

No quadro 1 foram listadas as características que podem ser exploradas na cadeia da carne bovina do Rio Grande do Sul para alavancar as exportações e gerar desenvolvimento no território, pela visão dos agentes entrevistados. As características citadas por ambos os grupos são semelhantes, sendo possível concluir que as especificidades da pecuária gaúcha e do território já estão consolidadas entre as distintas representações da cadeia. 
Quadro 1 - Características* do território gaúcho a serem exploradas na cadeia da carne bovina na visão de diferentes atores.

\begin{tabular}{|c|c|}
\hline Produtor Rural & $\begin{array}{l}\text { Entidades Apoio- Indústria } \\
\text { Frigorífica }\end{array}$ \\
\hline $\begin{array}{l}\text { Tipo de solo e pastagens naturais } \\
\text { (10) }\end{array}$ & $\begin{array}{l}\text { História, cultura, vocação e } \\
\text { tradição do povo gaúcho na } \\
\text { produção pecuária (12) }\end{array}$ \\
\hline $\begin{array}{l}\text { Aspectos geográficos (8); Cultura e } \\
\text { tradição do povo gaúcho na } \\
\text { produção pecuária (8) }\end{array}$ & $\begin{array}{l}\text { Tipo de solo e pastagens } \\
\text { naturais (11) }\end{array}$ \\
\hline $\begin{array}{l}\text { Clima favorável à criação de raças } \\
\text { europeias (5); Bioma Pampa (4); }\end{array}$ & Bioma Pampa (4) \\
\hline $\begin{array}{l}\text { Genética e raças europeias (3); } \\
\text { Utilização sustentável dos recursos } \\
\text { naturais/preservação ambiental (3) }\end{array}$ & $\begin{array}{l}\text { Clima favorável à criação de } \\
\text { raças europeias (2); Produção } \\
\text { sustentável (2) }\end{array}$ \\
\hline $\begin{array}{l}\text { Cultura do consumo de } \\
\text { carne/cultura do churrasco (2) }\end{array}$ & $\begin{array}{l}\text { Turismo rural associado à } \\
\text { produção (2) }\end{array}$ \\
\hline $\begin{array}{l}\text { Semelhança com os padrões de } \\
\text { produção do Uruguai e Argentina } \\
\text { (2) }\end{array}$ & $\begin{array}{l}\text { Semelhança com os padrões } \\
\text { de produção do Uruguai e } \\
\text { Argentina (1); Genética e } \\
\text { raças europeias (1) }\end{array}$ \\
\hline $\begin{array}{l}\text { Criação extensiva/baixo custo de } \\
\text { produção ( } 2 \text { ) }\end{array}$ & $\begin{array}{l}\text { Logística portuária (1) } \\
\text { Aspectos geográficos (1), }\end{array}$ \\
\hline $\begin{array}{l}\text { Bom acesso aos terminais de } \\
\text { exportação, com distâncias } \\
\text { razoáveis (2); Potencial hídrico (2), }\end{array}$ & $\begin{array}{l}\text { Exportação de produtos com } \\
\text { maior valor agregado, setor } \\
\text { primário em crescimento (1) }\end{array}$ \\
\hline $\begin{array}{l}\text { Precipitações geralmente bem } \\
\text { distribuídas (1); A mão de obra } \\
\text { barata e qualificada nos frigoríficos } \\
\text { (1) }\end{array}$ & $\begin{array}{l}\text { Integração com outras cadeias } \\
\text { produtivas (1) }\end{array}$ \\
\hline
\end{tabular}

*Valores entre parênteses referem-se ao número de citações realizadas.

Estes resultados confirmam a importância de se compreender o território como uma construção social, com a necessidade de interpretar o ambiente geográfico, para se incluir particularidades locais no global, com o desenvolvimento das potencialidades, gerando valor e visibilidade. É importante destacar que o território também possui uma menção globalizada, capaz de ser contestada através da possibilidade de diferenciar e valorizar as peculiaridades locais e regionais, no confronto à ideia de uniformidade da globalização. Significa contrapor o local ao global e compreender que as estratégias locais retroagem em relação às 
forças globais, levando-as a redirecionar suas leis de funcionamento, e então dar início a um movimento independente de crescimento e de autorregulação.

Diante do exposto, torna-se imprescindível olhar mais atentamente para todas estas questões, pois não há relevância produzir uma carne diferenciada, com custos mais altos, se não resulta em maior valorização do produto final. É fundamental que o estado e os agentes, não só reconheçam esses atributos do território e diferencial do produto nele gerado, como adotem uma postura ativa e responsável de explorá-los e valorizá-los a fim de aumentar a produção em termos de valor agregado, obtendo maior acesso a nichos de mercados, com reconhecimento internacional convertidos em ganhos financeiros.

Por sua vez, a Tabela 1 lista os principais pontos fortes e fracos da bovinocultura de corte do Rio Grande do Sul na percepção da amostra pesquisada. Em relação aos fatores potenciais, é possível notar que apenas os quatro primeiros itens elencados obtiveram médias superiores a quatro, considerados como importantes.

A partir destes resultados é possível concluir que os pontos fortes que obtiveram as maiores médias são fatores endógenos, ou seja, são forças geradas a partir do local, pelos agentes que trabalham diretamente na produção, o que vai ao encontro da importância do desenvolvimento territorial na construção de uma cadeia sólida com vistas ao mercado externo.

Os demais pontos citados, com exceção da expressão das associações de produtores, são fatores que dependem de forças externas para se desenvolverem, como políticas públicas e econômicas. 
Tabela 1 - Grau de importância de fatores potenciais e limitantes para a bovinocultura de corte do Rio Grande do Sul

\begin{tabular}{|c|c|}
\hline Fatores Potenciais & Média* $^{*}$ \\
\hline Possibilidade de integração lavoura-pecuária & 4,38 \\
\hline Genética dos rebanhos & 4,12 \\
\hline Boas condições de clima, solo e vegetação & 4,11 \\
\hline Nutrição em campo nativo & 4,05 \\
\hline Indicação de Procedência da "Carne do Pampa Gaúcho" & 3,95 \\
\hline Cultura e a tradição do povo gaúcho & 3,91 \\
\hline $\begin{array}{l}\text { Similaridade com os padrões de produção do Uruguai e da } \\
\text { Argentina }\end{array}$ & 3,77 \\
\hline Presença de indústria exportadora & 3,63 \\
\hline $\begin{array}{l}\text { O suporte científico-tecnológico da EMBRAPA e } \\
\text { Universidades }\end{array}$ & 3,55 \\
\hline Expressão das Associações de Produtores & 3,38 \\
\hline Fatores Limitantes & Média \\
\hline $\begin{array}{l}\text { Falta de confiança e complementaridade entre os atores da } \\
\text { cadeia }\end{array}$ & 4,31 \\
\hline Perfil individualista e falta de cultura cooperativa & 4,18 \\
\hline Assimetria de informações na cadeia produtiva & 4,05 \\
\hline Abate clandestino e informal & 3,88 \\
\hline Mão de obra pouco qualificada & 3,88 \\
\hline $\begin{array}{l}\text { Fragilidade nas "turbulências" do status sanitário e políticas } \\
\text { econômicas }\end{array}$ & 3,80 \\
\hline Baixa eficiência produtiva e econômica da atividade & 3,77 \\
\hline $\begin{array}{l}\text { Dificuldade no processo de rastreabilidade e padronização } \\
\text { dos rebanhos }\end{array}$ & 3,77 \\
\hline $\begin{array}{l}\text { Uso restrito de tecnologias de produção/predomínio da } \\
\text { pecuária extensiva }\end{array}$ & 3,66 \\
\hline Capacidade ociosa da indústria frigorífica & 3,33 \\
\hline
\end{tabular}

Escala do tipo likert de 5 pontos (1 a 5), sendo que 1 refere-se a "nada importante", e 5 refere-se a "muito importante"

Nos pontos limitantes é possível verificar a mesma lógica, na qual os três primeiros fatores citados com médias superiores a quatro, ou seja, importantes, são de caráter endógeno, considerados como fraquezas da cadeia. São eles: falta de confiança e complementaridade entre os atores da cadeia, perfil individualista e 
falta de cultura cooperativa, assimetria de informações na cadeia produtiva. Estes fatores devem ser solucionados internamente, com união e cooperação entre os agentes, a partir de objetivos comuns e compartilhados entre todos os elos em prol do fortalecimento da cadeia e o consequente ganho e valorização de mercado.

Os demais pontos limitantes, a exceção da baixa eficiência produtiva, são considerados variáveis exógenas, influenciados por oportunidades ou ameaças externas, como acordos comerciais, barreiras protecionistas, apoio governamental, políticas públicas sociais econômicas, o que mesmo assim não isenta a responsabilidade dos agentes. Complementarmente, a amostra da pesquisa listou alternativas para alavancar os pontos fortes, bem como propôs ações a serem trabalhadas a fim de combater as deficiências na cadeia e fortalecer o setor, descritas no quadro 2.

Quadro 2 - Estratégias para a cadeia de carne bovina do Rio Grande do Sul

\begin{tabular}{|l|l|}
\hline Estratégias & Ações \\
\hline $\begin{array}{l}\text { Estratégias de } \\
\text { marketing }\end{array}$ & $\begin{array}{l}\text { Segmentação de mercados, diferenciação do } \\
\text { produto, desenvolvimento de marca e divulgação } \\
\text { direcionada. }\end{array}$ \\
\hline $\begin{array}{l}\text { Eficiência do } \\
\text { processo produtivo }\end{array}$ & $\begin{array}{l}\text { Melhorar os índices técnicos, intensificar o uso de } \\
\text { tecnologia, maior fertilidade do solo e nível } \\
\text { nutricional, padronizar o rebanho, diminuir idade de } \\
\text { abate e a sazonalidade. }\end{array}$ \\
\hline $\begin{array}{l}\text { União e cooperação } \\
\text { dos entes da cadeia }\end{array}$ & $\begin{array}{l}\text { Associativismo e cooperativismo, aumentar a } \\
\text { expressão das associações, reivindicação de } \\
\text { políticas públicas, maior comprometimento e } \\
\text { sensibilização dos agentes da cadeia, formação de } \\
\text { parcerias e alianças estratégicas. }\end{array}$ \\
\hline $\begin{array}{l}\text { Qualificação da } \\
\text { mão-de-obra e dos } \\
\text { demais agentes }\end{array}$ & $\begin{array}{l}\text { Programas de capacitação e assistência técnica, } \\
\text { promoção de palestras, cursos, treinamentos, } \\
\text { educação continuada, extensão das pesquisas } \\
\text { universitárias, maior integração pesquisa-campo. }\end{array}$ \\
\hline $\begin{array}{l}\text { Divulgação de } \\
\text { informações da } \\
\text { cadeia }\end{array}$ & $\begin{array}{l}\text { Promoção de fóruns, palestras, painéis de debate } \\
\text { com núcleos de associações, discussões entre os } \\
\text { elos da cadeia, mediação de interesses. }\end{array}$ \\
\hline $\begin{array}{l}\text { Apoio } \\
\text { governamental e } \\
\text { políticas públicas }\end{array}$ & $\begin{array}{l}\text { Subsídios financeiros, sistema de rastreabilidade } \\
\text { eficaz e confiável, defesa sanitária eficiente, maior } \\
\text { fiscalização no campo e na indústria. }\end{array}$ \\
\hline \multicolumn{2}{|l}{}
\end{tabular}

As estratégias elencadas buscam fortalecer a bovinocultura de corte em seu ambiente interno. No entanto, entende-se que o 
fortalecimento da atividade influenciará sua competitividade no mercado internacional. Assim, sob a ótica do mercado externo, a pesquisa buscou identificar o grau de concordância dos produtores rurais e entidades de apoio/indústria da cadeia bovina em relação às cinco vantagens geradas pelas exportações, discutidas por Souza (2002). A maioria dos fatores foi considerada importante, com média superior ou próxima a quatro, o que demonstra que mesmo o país tendo mercado interno aquecido os agentes percebem a importância das exportações.

Tabela 2 - Grau de concordância sobre as principais vantagens das exportações

\begin{tabular}{lc} 
Benefícios das exportações & Média* $^{\star}$ \\
\hline Melhorar os padrões de eficiência produtiva interna com o & 4,33
\end{tabular} aumento da competitividade do mercado externo

Gerar economias de escala/redução de custos produtivos $\quad 4,23$

e aumento da margem de lucro

Melhor aproveitamento dos recursos disponíveis no $\quad 4,17$ território

Gerar suporte tecnológico e econômico dentro das $\quad 4,09$ regiões produtoras

Complementar o mercado interno e reduzir capacidade $\quad 3,88$ ociosa

Escala do tipo likert de 5 pontos (1 a 5), sendo que 1 refere-se a "discordo totalmente", e 5 refere-se a "concordo totalmente"

A partir do estudo, é possível inferir que as estagnadas regiões de fronteira do Rio Grande do Sul, com predomínio da atividade pecuária, podem aumentar sua visibilidade no mercado internacional ao oferecerem uma carne de maior valor agregado, ao investir em um ramo que já possuem vocação, sendo capazes de valorizar sua atividade ao demonstrarem suas potencialidades territoriais. Assim, destaca-se a importância de se pensar e discutir fatores territoriais para agregação aos produtos. Por exemplo, aqueles produtores que desenvolvem a pecuária por tradição, vocação ou satisfação estariam incluindo uma nova característica ao produto, que possivelmente possa ser comunicada e valorizada no mercado externo. Podem-se somar a este exemplo outras características do território, como o bioma pampa, o bem-estar 
animal, a cultura do gaúcho, etc., possibilitando assim 0 fortalecimento da cadeia e o crescimento da produção.

Essa valorização e consciência dos agentes auxilia na descoberta de potenciais que até o momento o meio rural não havia desvendado à sociedade. Isso permite que o meio rural passe a ser entendido como a base de um conjunto variado de atividades, funções e mercados em potencial, e não mais como uma simples sustentação geográfica de um segmento (a agricultura ou pecuária), ampliando os horizontes de valorização de produtos agropecuários.

Os elementos do território apresentados na Tabela 3 foram baseados nos conceitos de Schejtman e Berdegué (2003) e Schneider (2004), que consideram estes como modos e particularidades com que acontece o processo de intermediação dos territórios rurais com o ambiente externo.

Todos esses elementos foram considerados como importantes potencialidades para o desenvolvimento da cadeia e da região na visão da amostra entrevistada, comprovados através das médias com valores superiores.

Tabela 3 - Grau de importância de fatores do território para o fortalecimento da cadeia bovina.

Fatores territoriais Média

Valorização das características do meio rural, como

4,60

preservação do bioma, costumes, tradição, patrimônio

histórico, paisagístico, produtivo e cultural

Sentimento de identidade, construída socialmente, dos

4,52

agentes da cadeia pela sua terra/pelo seu território e pela

vocação pecuária

Indicação de procedência dos produtos

Inovação e disseminação de novas tecnologias

Novas formas de relacionamento entre produtores e $\quad 4,45$ consumidores

Importância das cadeias agro-industriais e do

abastecimento de matéria-prima para a sociedade

A pluriatividade no território rural como forma de diferenciar e complementar a atividade pecuária 
Sabe-se que o desenvolvimento do território só tem significado e êxito se proporcionar um ambiente sustentável, indo além do atendimento das necessidades pessoais. A produção de bovinos de corte se alia a esse conceito, na medida em que produz carne bovina predominantemente em campo nativo, preservando as tradições e os costumes, com um sentimento de identidade do gaúcho. Esses fatores do território podem ser certificados com o uso da indicação de procedência - a carne do pampa gaúcho - capaz de satisfazer um consumidor mais seletivo e consciente dos desafios sustentáveis.

Sendo assim, é imprescindível o tipo de ação, passiva ou ativa, adotada por essas regiões em prol do desenvolvimento, principalmente pelos agentes da cadeia da carne bovina, diante da acirrada competição global, pois o território é responsável por construir estratégias desenvolvimentistas que trazem benefícios ou malefícios, capazes de transformá-lo em um território do tipo "inovador/ganhador" ou "submisso/perdedor". Além disso, as soluções e respostas aos problemas existentes nessas regiões encontram-se nela mesmo.

Portanto, a pecuária, sendo uma das principais atividades da região sul do Rio Grande do Sul, pode se beneficiar do dinâmico mercado externo de carnes brasileiro se der especial atenção aos fatores territoriais como diferenciais de valor. No entanto, cabe destacar que, agir passivamente e adotar posturas despreocupadas, apenas confiando nas potencialidades, não serão meios adequados para desenvolvê-los.

A partir do estudo acredita-se que tanto o território como o mercado externo podem trazer benefícios mútuos à cadeia produtiva da carne gaúcha, no qual o território pode auxiliar na valorização do produto, colaborando com a qualidade, benefícios, diferenciação e competitividade dos mesmos, assim como o mercado externo e as exportações, ao trazerem vantagens pelo aumento da eficiência produtiva e os efeitos da multiplicação de renda e emprego, capazes de auxiliarem no desenvolvimento da região.

\section{CONSIDERAÇÕES FINAIS}

A pesquisa buscou analisar a participação da produção de carne bovina gaúcha nas exportações brasileiras e contribuir na discussão sobre a inserção da bovinocultura de corte gaúcha no mercado externo a partir de características do território. Ao longo das discussões realizadas, foi verificado que a carne gaúcha, mesmo 
apresentando diferencial competitivo, não apresenta valorização superior, visto que os preços médios pagos pela carne do Rio Grande do Sul no mercado internacional são aproximadamente 10\% inferiores aos preços médios nacionais. Além disso, a participação do estado no rebanho efetivo nacional é superior a participação no total das exportações. Percebe-se, com isso, uma grande oportunidade para a pecuária de corte através da penetração em nichos de mercados específicos.

Através da percepção dos agentes sobre o diferencial, valorização da carne gaúcha no mercado externo, e as características do território, é possível afirmar que produtores e entidades/indústria demonstram similaridade nas opiniões, e consideram as variáveis endógenas da atividade as de maior importância para o fortalecimento do mercado bovino, o que pode ser considerado um fator positivo, devido ao fato de obterem uma visão consentida e da oportunidade de alavancar o setor através das forças locais, por meio de decisões e estratégias construídas mutuamente.

Entretanto, existe a necessidade de uma postura de cooperação e organização entre esses agentes econômicos, formando lideranças que representem o interesse de todos os envolvidos, com consenso e sinergia de esforços, para conseguir suprir essa demanda existente e potencial.

Uma das limitações do estudo foi o uso de uma amostra por conveniência, a qual não permitiu uma distribuição equivalente dos questionários e uma generalização dos resultados para a totalidade dos agentes da cadeia da bovinocultura de corte do Rio Grande do Sul. Como proposta para estudos futuros, sugere-se um aprofundamento sobre a análise da estrutura da cadeia e sua relação com o mercado externo a fim de entender as limitações do setor gaúcho em acessar mercados mais rentáveis. Ainda, destaca-se a necessidade de uma maior reflexão de como características territoriais podem ser trabalhadas a fim de agregar valor aos produtos da metade sul do Rio Grande do Sul.

\section{REFERÊNCIAS BIBLIOGRÁFICAS}

ABIEC, Associação Brasileira das Indústrias Exportadoras de Carnes. Estatísticas - Balanço pecuário - Fluxo da cadeia. Disponível em: <http://www.abiec.com.br/img/Upl/fluxo_por.pdf> Acesso em 27 out. 2012. 
ABRAMOVAY, R. O capital social dos territórios: repensando o desenvolvimento rural. In: Economia Aplicada, v. 4, n. 2, p. 379397, abr. / jun. 2000.

DALLABRIDA, V.R. A Gestão Social dos Territórios nos Processos de Desenvolvimento Territorial: Uma Aproximação Conceitual. Sociedade, Contabilidade e Gestão, Rio de Janeiro, v. 2, n. 2, segundo semestre de 2007.

DULLIUS, P.R.; FROEHLICH, J.M.; VENDRUSCOLO, R. Identidade e Desenvolvimento Territorial - Estudo das Experiências de Indicações Geográficas no Estado do RS. Anais... XLVI Congresso da SOBER (Sociedade Brasileira de Economia, Administração e Sociologia Rural) 2008, Rio Branco, Acre.

FAO. Publicações, 2013. OECD-FAO Agricultural Outlook 20102019. Acessado em 20 mar. 2013. Disponível em:

$<$ https://www.fao.org.br/download/OECDFAO_AgriculturalOutlook201 02019.pdf>

FREITAS, R.E. Exportações Agropecuárias: importância relativa e grupos de produtos. IPEA, Radar - Tecnologia, Produção e Comércio Exterior, № 20. 2012.

FÜRSTENAU, V. Pecuária de corte: baixos índices zootécnicos e eficiência no setor exportador. Indic. Econ. FEE, Porto Alegre, v. 32, n. 1, p. 265-292, maio 2004.

GEHLEN, I.; RIELLA, A. Dinâmicas territoriais e desenvolvimento sustentável. Sociologias, Porto Alegre, ano 6, n 11, jan/jun 2004, p. 20-26.

IBGE, Instituto Brasileiro de Geografia e Estatística. Downloads Estatística - Produção Pecuária - Pesquisa Trimestral do Abate de Animais. Disponível em: <http://www.ibge.gov.br/home/download/estatistica.shtm>. Acesso em 03 nov 2012.

JEAN, B. Du développement régional au développement territorial durable: vers un développement territorial solidaire pour réussir le développement des territoires ruraux. Coloquio Internacional de Desenvovimento Territorial Sustentavel 2009. Florionaopolis, SC. 
LIMA, L.C.O.; MACEDO, P.C.A. Sistema produtivo da carne bovina: oligopólio mundial, investimento estratégico e arena competitiva. Anais... 49ํ Congresso da SOBER (Sociedade Brasileira de Economia, Administração e Sociologia Rural) 2011, Belo Horizonte, MG.

MALAFAIA G.C.; BARCELLOS, J.O.J.; AZEVEDO, D.B. Construindo vantagens competitivas para a pecuária de corte do Rio Grande do Sul: o caso da indicação de procedência da "Carne do Pampa Gaúcho". In: SEMINÁRIOS EM ADMINISTRAÇÃO (SEMEAD), 9, 2006, São Paulo. Anais... São Paulo: Universidade de São Paulo, 2006.

MAPA. Estatísticas de Comercio Exterior do Agronegócio Brasileiro (AGROSTAT). Relatórios Gerenciais - Importação e Exportação. Ministério da Agricultura Pecuária e Abastecimento, 2012a. Disponível em: <http://sistemasweb.agricultura.gov.br/pages/AGROSTAT.html>. Acesso em 24 jun. 2012.

MAPA, Ministério da Agricultura Pecuária e Abastecimento. Animal Bovinos, 2012b. Disponível em: <http://www.agricultura.gov.br/animal/especies/bovinos-e-bubalinos>. Acesso em 05 nov 2012.

MULS, L.M. Desenvolvimento Local, Espaço e Território: O Conceito de Capital Social e a Importância da Formação de Redes entre Organismos e Instituições Locais. Revista Economia Janeiro/Abril 2008.

PAIVA, R.M. A agricultura no desenvolvimento econômico: suas limitações como fator dinâmico. IPEA série monográfica. Rio de Janeiro, RJ. 1979.

SCHEJTMAN, A. BERDEGUÉ, J. Desarrollo territorial rural. RIMISP, Santiago/Chile, febrero, 2003, 54 p.

SCHNEIDER, S. A abordagem territorial do desenvolvimento rural e suas articulações externas. Dossiê. Sociologias, Porto Alegre, ano 6, no 11 , jan/jun 2004, p. 88-125.

SOUZA, N.J. Desenvolvimento Regional. Editora Atlas. São Paulo, SP, 2009.

SOUZA, N.J. Exportações e Crescimento Econômico do RS - 19512001. Ensaios FEE. Porto Alegre, FEE, v.23, n. esp., 2002. 
UNFPA. População, 2013. Acessado em 20 mar. 2013. Disponível em: <http://www.unfpa.org.br/novo/index.php/populacao>. 